\title{
EP-209
}

\section{A glimpse to the resident life in a hepato-biliary-pancreatic team}

\author{
Mara MARDARE ${ }^{* 1}$, Alina PUSCASU', Victor BURLOIU', Andrei VACARASU', Irina BONDOC ${ }^{1}$, Andrada SPANU', \\ Razvan IOSIFESCU', Marius ZAMFIR', Niculae IORDACHE', Octav GINGHINA', Radu GHENADE', Camelia CALIN² \\ 'Department of General Surgery, St John Emergency Hospital, Bucharest, Rumania \\ ${ }^{2}$ Department of Anesthesiology, St John Emergency Hospital, Bucharest, Rumania
}

Introduction: What does hepato-biliary-pancreatic (HBP) surgery mean and how does the life of the resident in a young team practicing such surgery in a developing country look like?

Methods: Surgical residents interested in acquiring advanced training in HBP surgery should take a fellowship in this kind of surgery, spending at least four years in a specialized center.

Results: The pre and postoperative management of patients is a core function of a junior doctor, but they have to be involved in every step of the journey represented by complex HBP surgery: from establishing anesthesia routine to training team and taking part in tumor board meetings. Mentorship is also a key factor in promoting and maintaining fulfillment in surgical practice.

Conclusions: In a young HBP team, bidirectional growth - both mentors and residents is crucial to developing this king of surgery. Working hard, studying and training every day are very important steps in order to build a career as a HBP surgeon. 